Proc. of JSCE,

No. 164, 1969-4

\title{
EXPERIMENTAL STUDY FOR DERAILMENT ON VIBRATING TRACKS
}

\author{
By Yoshinosuke Yasoshima*, Yoshiji Matsumoto** and Takashi Nishioka***
}

\section{INTRODUCTION}

The behaviour of railway vehicles running through bridges is dominated by the forced vibration due to vibrating tracks in addition to the free vibration of railway vehicles. On the running of railway vehicles through long-span bridges such as suspension bridges, its comparatively small rigidity will induce the large deformation of tracks owing to the large load intensity of railway vehicles, which causes various influences on the stable running of railway vehicles. If these problems were solved, it would be possible to use the bridges with small rigidity as railway bridges.

It is a purpose of this paper to report the dynamic behaviour of four-wheeled railway vehicles on vibrating tracks through experiments. A series of tests was carried out with a vibration testing machine on which two types of model vehicles were laid. On vibrating tracks as well as usual railway tracks there are at least two limits for stable running. The first, or the upper, is the safety limit for derailment above which the running of vehicles should not be considered. The second is the allowable limit for the comfort of passengers. The main feature discussed in the following is that of the upper limit of stability. From a fundamental point of view, it will be important to investigate the safety limit for derailment in order to make clear of the stable running of railway vehicles on vibrating tracks. Further extensive experiments and theoretical analyses are now being carried out to investigate the dynamic response of railway vehicles on vibrating tracks.

This paper was prepared mainly by T. Nishioka under the guidance of Y. Yasoshima and Y. Matsumoto.

* Prof., Dep. of Civil Eng., University of Tokyo, D. Eng.

** Associate Prof. Dep. of Civil Eng. University of Tokyo, D. Eng.

*** Graduate Student of University of Tokyo, M.Eng.

\section{ASPECTS OF EXPERIMENT}

The dynamic stability of four-wheeled vehicles running through vibrating tracks was investigated experimentally using the vibration testing machine with the track of $17 \mathrm{~m}$ in length, on which one-fifth scale model vehicles are laid. Two types of vehicles were simulated to the existing railway vehicles now being used by the Japanese National Railways. They were designed so as to preserve the dynamical similitude with the existing vehicles. Table 1 shows the scale factor used to design these vehicles.

The lateral suspension for each type of vehicles is different from each other. The stiffness of vehicle A consists of one-linked suspension. Therefore, restraint is provided laterally as a result of its suspension design. On the other hand, the stiffness of vehicle B consists of two-linked suspension which is free to swing both laterally and longitudinally. In both vehicles, the height and deviation in horizontal plane of the center of gravity are designed to

Table 1 Scale Factor of Model Vehicles

\begin{tabular}{l|c|c|c|c|c|c}
\hline & Length & $\begin{array}{r}\text { Accelera- } \\
\text { tion }\end{array}$ & Velocity & $\begin{array}{r}\text { Fre- } \\
\text { quency }\end{array}$ & Mass & Stiffness \\
\hline $\begin{array}{l}\text { Scale } \\
\text { Factor }\end{array}$ & $1 / 5$ & $1 / 1$ & $1 / 5$ & 5 & $1 / 125$ & $1 / 25$ \\
\hline
\end{tabular}

Table 2 Prameters of model vehicles

\begin{tabular}{l|l|l}
\hline & Vehicle A & \multicolumn{1}{|c}{ Vehicle B } \\
\hline Vertical spring constant & $3.24 \mathrm{~kg} / \mathrm{mm}$ & $3.61 \mathrm{~kg} / \mathrm{mm}$ \\
Lateral spring constant & - & $0.5 \mathrm{~kg} / \mathrm{mm}$ \\
Vertical damping codfficient & $0.057 \mathrm{~kg} \mathrm{sec} / \mathrm{cm}$ & $0.038 \mathrm{~kg} \mathrm{sec} / \mathrm{cm}$ \\
Weight of body frame & $46.8 \mathrm{~kg}$ & $58.2 \mathrm{~kg}$ \\
Weight of wheelsets & $14.4 \mathrm{~kg}$ & $14.4 \mathrm{~kg}$ \\
Wheel base & $780 \mathrm{~mm}$ & $1150 \mathrm{~mm}$ \\
Spring base & $386 \mathrm{~mm}$ & $386 \mathrm{~mm}$ \\
Moment of inertia of body & & \\
frame; longitudinal & $10600 \mathrm{~kg} \cdot \mathrm{cm}^{2}$ & $9870 \mathrm{~kg}-\mathrm{cm}^{2}$ \\
$\quad$ lateral & $78000 \mathrm{~kg}-\mathrm{cm}^{2}$ & $195000 \mathrm{~kg} \cdot \mathrm{cm}^{2}$ \\
$\quad$ vertical & $88600 \mathrm{~kg}-\mathrm{cm}^{2}$ & $205000 \mathrm{~kg} \cdot \mathrm{cm}^{2}$ \\
Moment of inertia of Wheelsets & & \\
$\quad$ longitudinal & $794 \mathrm{~kg} \cdot \mathrm{cm}^{2}$ & $794 \mathrm{~kg} \cdot \mathrm{cm}^{2}$ \\
$\quad$ lateral & $119 \mathrm{~kg} \cdot \mathrm{cm}^{2}$ & $119 \mathrm{~kg} \cdot \mathrm{cm}^{2}$ \\
\hline
\end{tabular}




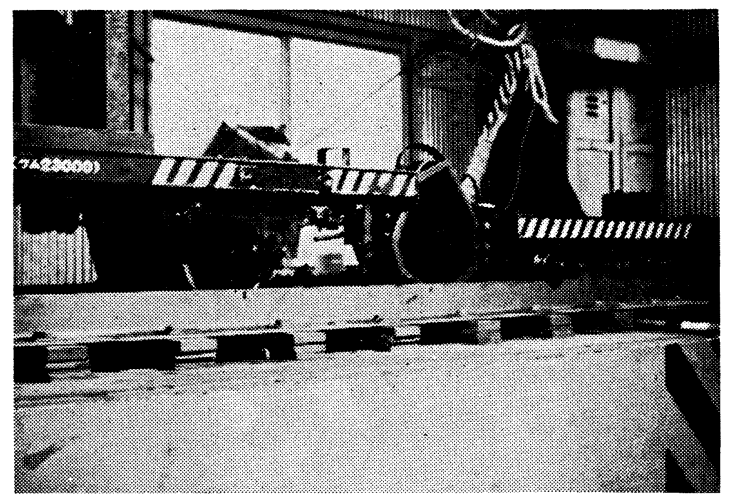

Photo 1 Model vehicle and leading car.

select their suitable positions. The inertia of vehicles can be also varied with loading weights. The vehicles are pulled by the leading car, of which velocity can be varied up to $4 \mathrm{~m} / \mathrm{sec}$. The parameters of vehicles are given in Table 2 . These were established by various kinds of measurement. The spring and damping parameters were measured both dynamically and statically, but serious differences were not observed. The method applied to the measurement of moment of inertia is due to the principle of the phisical pendulum. When swaying frequencies about two reference points of a rigid body are obtained, its moment of inertia will be calculated. These values are set out in Table 2 .

The testing machine used in the experiment is able to vibrate the track with a given sinusoidal wave both in the vertical and lateral directions. The frequency of the vibrating track, which ranged from $0 \mathrm{c} / \mathrm{s}$ to $1.0 \mathrm{c} / \mathrm{s}$ both vertically and horizontally, is controlled by electromagnetic induction motors. The amplitude of the vibrating track can be changed from $5 \mathrm{~cm}$ to $10 \mathrm{~cm}$ in both directions.

\section{TYPES OF DERAILMENT OBSERVED IN EXPERIMENT}

The behaviour of a running wheel tread of the model vehicle was always observed through experiment by $16 \mathrm{~mm}$ movie camera which was mounted on the leading car. The derailment observed were classified into three categories in a consequence of studying a number of films. They were named 'Climbing-up Derailment' 'Floating-up Derailment' and 'Rocking Derailment' respectively. These are defined as follows.

\section{(1) Climbing-up Derailment}

A flange of the wheelsets climbs up, or slides up along the side of the rail. According to a considerable amount of data, the time required for the climbing or sliding process was about $0.12 \mathrm{sec}$. It seems to be the same type of derailment that is dealed

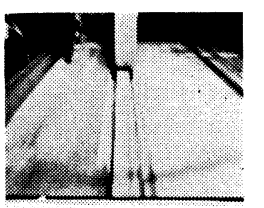

Normal running
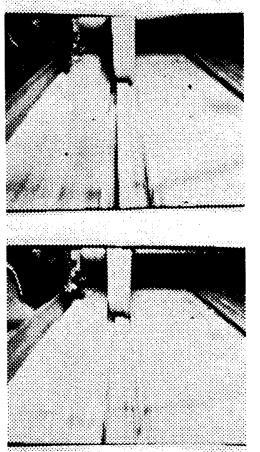

Flange climbing-up suddenly
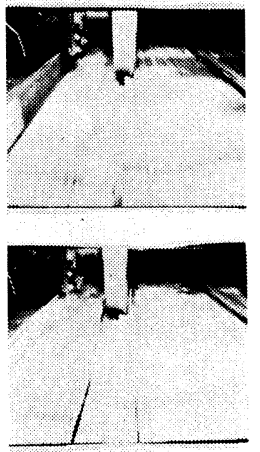

Flange running on rail head
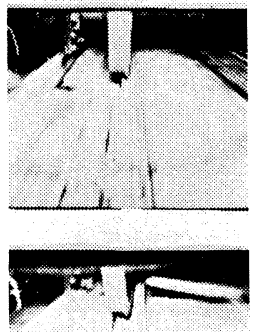

Derailment

Eig. 1 Climbing-up Derailment.

with the Nadal's formula, because the flange is always contact with the rail in the process of derailment. Therefore, the force at the wheel-to-rail contact owing to the external vibration force might be dependent on the mutual geometry of tyres and rail heads in case of the climbing-up derailment.

\section{(2) Floating-up Derailment}

Differently from the climbing-up derailment, the floating-up derailment occurs without contact between flanges and rails. The time required for the floating of flanges to rail heads was about $0.18 \mathrm{sec}$. When 


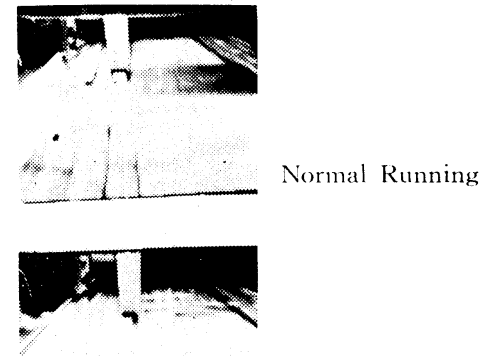

Wheel floating up suddenly
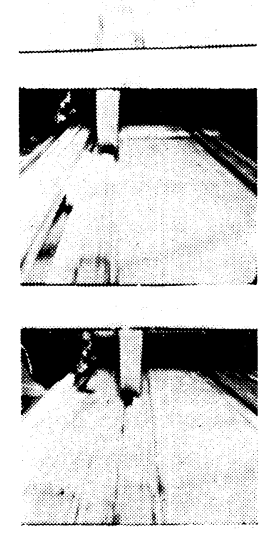

Flange falling down on rail head
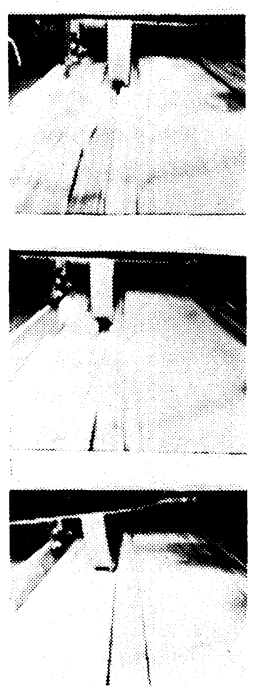

Derailment

Fig. 2 Floating-up Derailment.

the wheel is floating up in the process of derailment, the movement of the body seems almost negligible compared with the rotating angle of wheelsets.

\section{(3) Rocking Derailment}

The rocking derailment is defined as the repetition of rocking motion which causes finally to derail or overturn. It is distinctly different from other two types of derailments because of its violent rocking motion of the body. In the rocking motion of the vehicle, the rocking phase of the body are the same that of the wheclsets.

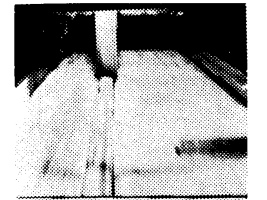

Rocking motion already started

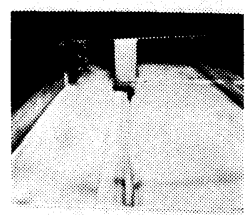

Body frame sinking

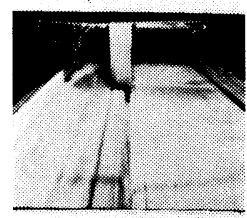

Body frame sinking

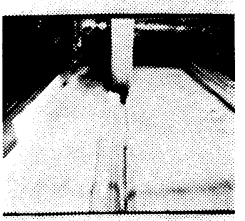

Body frame and wheelsets floating up

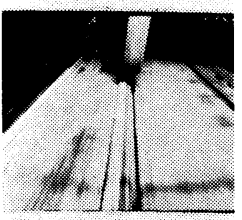

Same phase of wheelcets to body frame
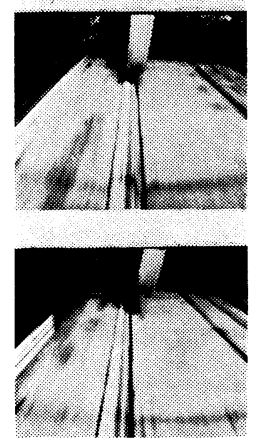

Turnover

Fig. 3 Rocking Derailment.

Fig. 1,2 and 3 show three types of the derailment observed by films.

\section{EFFECTS OF LATERAL AND VERTICAL ACCELERATION OF TRACK.}

Each model vehicle was made to run in turn at a given constant speed over the test track specially laid on the testing machine. They were tested in various conditions to investigate the running stability on the tracks with various irregularities. The track was 
vibrated in vertical and horizontal directions with many combinations of acceleration. The stability of model vehicles was examined over a range of speed and recorded the resultant response of lateral and vertical directions.

As a result of the experiment, it is noteworthy that the lateral acceleration of the track greatly influences on the motion of model vehicles. As the height of the center of gravity above the level of rail-to-wheel contact point increases, the lateral acceleration of vibrating tracks produces rotating moment around the longitudinal axis through the center of gravity of the vehicle. Since the body of the vehicle is supported with lateral and vertical springs, its rotating moment produces two types of vibrations of the body. One is so-called 'lower center rolling' and the other, 'upper center rolling'. The natural frequencies of the body on the suspension with wheels fixed in the model vehicle $\mathbf{B}$ were about $1.5 \mathrm{c} / \mathrm{s}$ the lower center rolling, and about $4.0 \mathrm{c} / \mathrm{s}$ the upper center rolling, which coincide nearly with theoretical values.

On the other hand, compared with the lateral acceleration, the vertical acceleration of the vibrating track might not have remarkable influence on the rotating moment of vehicles without the large deviation of the center of gravity in horizontal plane, which is caused by the way of loading. The center of gravity is not so deviated in the horizontal plane as in the height, because the width and length of bodies are limited by the design of vehicles.

These tendencies in connection with derailment are illustrated in Fig. 4 and Fig. 5. The experiments were carried out on the plain tracks with no irregularity in both vehicle $\mathbf{A}$ and vehicle $\mathbf{B}$. It

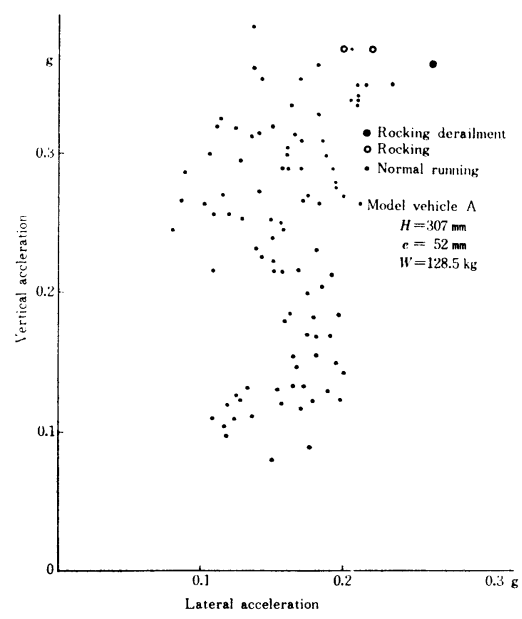

Fig. 4

$H$ : Height of the center of gravity above track level $e$ : Lateral deviation of the center of gravity

$W:$ Weight of load

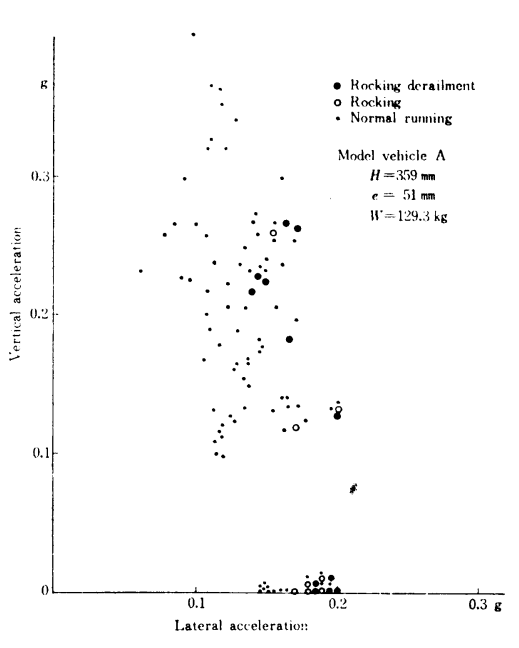

Fig. 5

should be noted that vertical acceleration has not so serious influence on the instability of vehicles as lateral acceleration. In comparison between Fig. 4 and Fig. 5, it is clear that the instability depends greatly on the height of the center of gravity.

In both cases the unstable behaviour of vehicles was limited only to rocking motion and the rocking derailment. As the lateral external acceleration associated with the vehicle instability increases, the rolling motion of the vehicle becomes increasingly violent until the slipping of wheel treads commences. The mode of rocking motion at this stage nearly coincides with that of lower center rolling. Once the flange of wheelsets started to strike the side of rails, the rolling motion grew up to rocking motion. Frequency of rocking motion was almost equal to that of the external vibration which ranged from $0.6 \mathrm{c} / \mathrm{s}$ to $1.0 \mathrm{c} / \mathrm{s}$.

It has been found that the amplitude of rocking motion decreases gradually as the running velocity increases. The relation between the running velocity of vehicles and the rocking derailment are illustrated

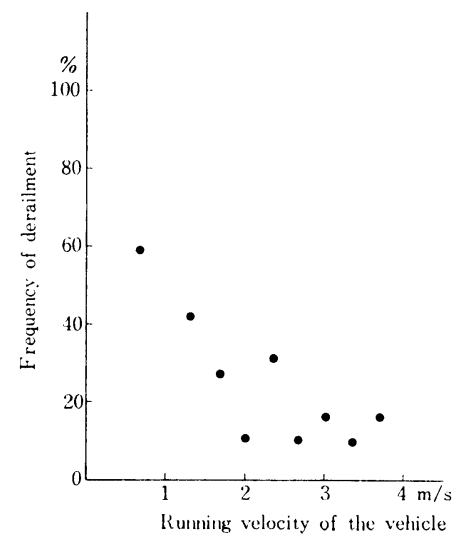

Fig. 6 
in Fig. 6. The ordinate indicates the percentage of the rocking derail' ment to the number of the total running. The lateral acceleration of vibrating tracks was decided with the acceleration at the time when the vehicle slightly shows rocking motion on stationary condition. It is obvious that the stability of vehicles increases with running velocity.

\section{INFLUENCE OF IRREGULARITY IN TRACKS}

In addition to the vertical and lateral acceleration of the track, the derailment on vibrating tracks results from a number of other causes and these combinations. The shape of tracks seem to play one of the most significant roles on the stability of railway vehicles. In connection with the lateral acceleration of the track, the influence of irregularity on both rails with lateral alignment was investigated. The extraordinary amplitude of irregularity in com-

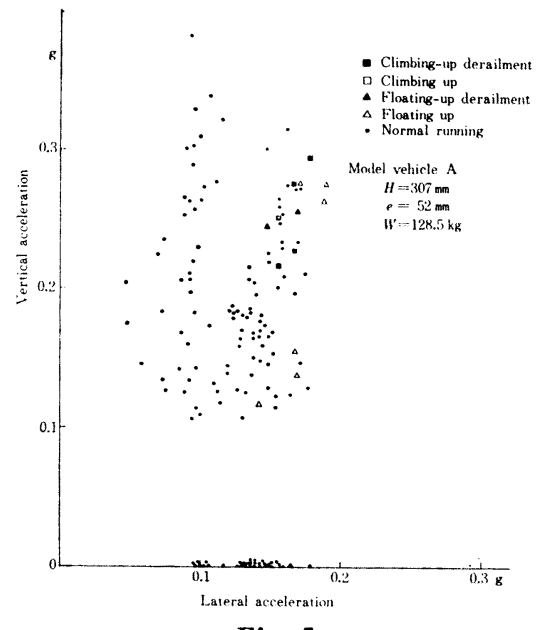

Fig. 7

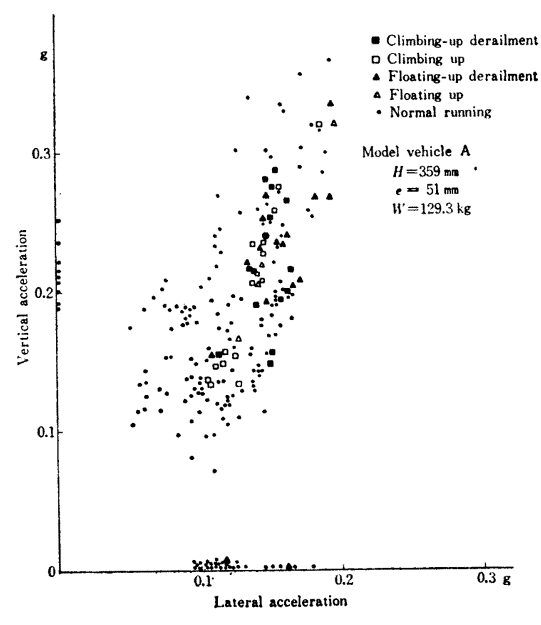

Fig. 8 parison with the usual railway tracks was used in order to cause serious conditions of railway vehicles (amplitude $\pm 13.5 \mathrm{~mm}$, wave length $3.6 \mathrm{~m}$ ). The results are shown in Fig. 7 and Fig. 8. A considerable number of the climbing-up and floating-up derailments arise in these cases. It will be obvious that so far as the climbing-up and floating-up derailments are concerned, the tendencies to derail depend considerably on the lateral alignment irregularities.

In order to make clear of the relationship between these derailments and the alignment of tracks, the starting position of derailment on the track was examined by films. Fig. 9 shows the alignment of the tracks and the position where derailment started. While it is not distinct where the floating-up derailment occurs, the climbing-up derailment is confined at its starting position. It means that the climbing -up derailment is related to the angle of wheelsets against rails. The most of the climbing-up derailment occurred under the leading right wheel. It will be reasonable to estimate that wheel load decreased under right wheels to the left owing to the deviation of the center of gravity, because

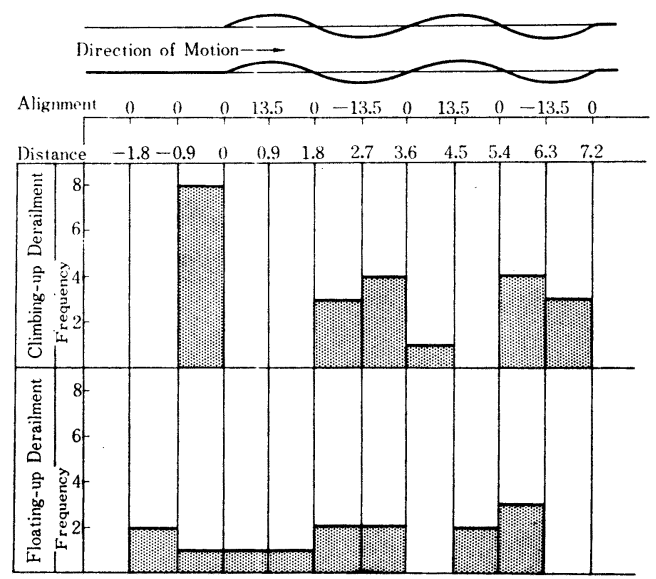

Fig. 9 Position of Derailment

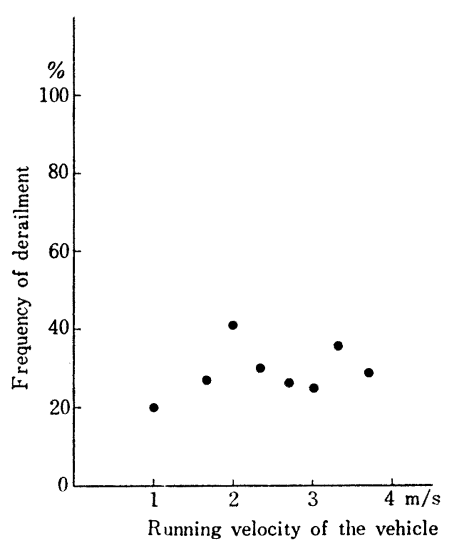

Fig. 10 
the center of gravity was deviated about $51 \mathrm{~mm}$ to the left side of running direction.

Fig. 10 illustrates the relationship between the running velocity of vehicles and derailment, which was tested on the same track with lateral alignment irregularity. Different from the case of the plain track shown in Fig. 6, the derailment has no relation to the running velocity of vehicles in this case. In both floating-up and climbing-up derailments, when wheels are floating or climbing-up to rail heads in the process of derailment, the rolling phase of vibration in the body seems almost negligible, or slightly adverse to the wheelsets. It means that the mode of the floating-up derailment and the climbing-up derailment differ from that of the rocking derailment.

\section{CONCLUSION}

The experimental investigation discussed in this paper shows that the lateral motion of tracks has serious influence on the stability of railway vehicles and that the unstable running is dependent greatly on the mode of vibration between wheelsets and bodies of vehicles. The extension of these analyses should be required to cover further quantitative knowledge for the stability of railway vehicles on vibrating tracks. As a result of the experiment, it is mentioned that the study for derailment should be considered dynamically by use of the whole vibrating systems of vehicles and tracks.

\section{ACKNOWLEDGEMENTS}

The authors wish to thank the Japanese National Railways and the Japan Railway Construction Corporation for the opportunity to publish this paper. Grateful acknowledgement is also made to members of Traffic Laboratory, Depaıiment of Civil Engineering, University of Tokyo for the contribution of this works.

\section{REFERENCE}

1) Yasoshima, Y. : 'Study for Tracks on Suspension Bri dges and Running Stability of Railway Vehicles' (I, II, III, IV) Reports submitted to the J.R.C.C. (in Japanese) 1963 1966.

2) Matsudaira, T. : 'Nosing of 2-axle Railway Cars and its prevention' Trans. of Japan Society of Mechanical Engineering. Vol. 19, No. 87 (in Japanese)

3) Okijima, K.: 'Causes of Train Derailment and its Prevention' (in Japanese)

4) Yasoshima, Y. and others. : The report in the 22 th Annual Meeting of Japan Society of Civil Engineering. 1967.
(Receved Sept. 3, 1968) 